\title{
A novel method for engineering autologous non- thrombogenic in situ tissue-engineered blood vessels for arteriovenous grafting
}

\author{
Citation for published version (APA):
}

Geelhoed, W. J., van der Bogt, K. E. A., Rothuizen, T. C., Damanik, F. F. R., Hamming, J. F., Mota, C. D., van Agen, M. S., de Boer, H. C., Restrepo, M. T., Hinz, B., Kislaya, A., Poelma, C., van Zonneveld, A. J., Rabelink, T. J., Moroni, L., \& Rotmans, J. I. (2020). A novel method for engineering autologous nonthrombogenic in situ tissue-engineered blood vessels for arteriovenous grafting. Biomaterials, 229, [119577]. https://doi.org/10.1016/j.biomaterials.2019.119577

Document status and date:

Published: 01/01/2020

DOI:

10.1016/j.biomaterials.2019.119577

Document Version:

Publisher's PDF, also known as Version of record

\section{Document license:}

Taverne

Please check the document version of this publication:

- A submitted manuscript is the version of the article upon submission and before peer-review. There can be important differences between the submitted version and the official published version of record.

People interested in the research are advised to contact the author for the final version of the publication, or visit the DOI to the publisher's website.

- The final author version and the galley proof are versions of the publication after peer review.

- The final published version features the final layout of the paper including the volume, issue and page numbers.

Link to publication

\footnotetext{
General rights rights.

- You may freely distribute the URL identifying the publication in the public portal. please follow below link for the End User Agreement:

www.umlib.nl/taverne-license

Take down policy

If you believe that this document breaches copyright please contact us at:

repository@maastrichtuniversity.nl

providing details and we will investigate your claim.
}

Copyright and moral rights for the publications made accessible in the public portal are retained by the authors and/or other copyright owners and it is a condition of accessing publications that users recognise and abide by the legal requirements associated with these

- Users may download and print one copy of any publication from the public portal for the purpose of private study or research.

- You may not further distribute the material or use it for any profit-making activity or commercial gain

If the publication is distributed under the terms of Article $25 \mathrm{fa}$ of the Dutch Copyright Act, indicated by the "Taverne" license above, 


\title{
A novel method for engineering autologous non-thrombogenic in situ tissue- engineered blood vessels for arteriovenous grafting
}

\author{
W.J. Geelhoed ${ }^{\mathrm{a}, \mathrm{b}}$, K.E.A. van der Bogt ${ }^{\mathrm{c}}$, T.C. Rothuizen ${ }^{\mathrm{a}}$, F.F.R. Damanik ${ }^{\mathrm{d}}$, J.F. Hamming ${ }^{\mathrm{c}}$, \\ C.D. Mota ${ }^{\mathrm{d}}$, M.S. van Agen ${ }^{\mathrm{a}, \mathrm{b}}$, H.C. de Boer ${ }^{\mathrm{a}, \mathrm{b}}$, M. Tobón Restrepo ${ }^{\mathrm{e}}$, B. Hinz ${ }^{\mathrm{f}}$, A. Kislaya ${ }^{\mathrm{g}}$, \\ C. Poelma ${ }^{\text {g }}$, A.J. van Zonneveld ${ }^{\mathrm{a}, \mathrm{b}}$, T.J. Rabelink ${ }^{\mathrm{a}}$, L. Moroni ${ }^{\mathrm{d}}$, J.I. Rotmans ${ }^{\mathrm{a}, *}$ \\ ${ }^{a}$ Department of Internal Medicine, Leiden University Medical Center, the Netherlands \\ ${ }^{\mathrm{b}}$ Einthoven Laboratory of Vascular and Regenerative Medicine, the Netherlands \\ ${ }^{\mathrm{c}}$ Department of Surgery, Leiden University Medical Center, the Netherlands \\ ${ }^{\mathrm{d}}$ MERLN Institute for Technology-Inspired Regenerative Medicine, Maastricht University, Maastricht, the Netherlands \\ ${ }^{\mathrm{e}}$ Division of Diagnostic Imaging, Faculty of Veterinary Medicine, Utrecht University, Utrecht, the Netherlands \\ ${ }^{\mathrm{f}}$ Laboratory of Tissue Repair and Regeneration, Faculty of Dentistry, University of Toronto, Canada \\ ${ }^{\mathrm{g}}$ Laboratory for Aero and Hydrodynamics, Delft University of Technology, Delft, the Netherlands
}

\section{A B S T R A C T}

The durability of prosthetic arteriovenous (AV) grafts for hemodialysis access is low, predominantly due to stenotic lesions in the venous outflow tract and infectious complications. Tissue engineered blood vessels (TEBVs) might offer a tailor-made autologous alternative for prosthetic grafts. We have designed a method in which TEBVs are grown in vivo, by utilizing the foreign body response to subcutaneously implanted polymeric rods in goats, resulting in the formation of an autologous fibrocellular tissue capsule (TC). One month after implantation, the polymeric rod is extracted, whereupon TCs (length $6 \mathrm{~cm}$, diameter $6.8 \mathrm{~mm}$ ) were grafted as arteriovenous conduit between the carotid artery and jugular vein of the same goats. At time of grafting, the TCs were shown to have sufficient mechanical strength in terms of bursting pressure $(2382 \pm 129 \mathrm{mmHg}$ ), and suture retention strength (SRS: $1.97 \pm 0.49 \mathrm{~N})$. The AV grafts were harvested at 1 or 2 months after grafting. In an ex vivo whole blood perfusion system, the lumen of the vascular grafts was shown to be less thrombogenic compared to the initial TCs and ePTFE grafts. At 8 weeks after grafting, the entire graft was covered with an endothelial layer and abundant elastin expression was present throughout the graft. Patency at 1 and 2 months was comparable with ePTFE AV-grafts. In conclusion, we demonstrate the remodeling capacity of cellularized in vivo engineered TEBVs, and their potential as autologous alternative for prosthetic vascular grafts.

\section{Statement of significance}

Tissue engineered blood vessels are considered a promising alternative for prosthetic vascular grafts as arteriovenous vascular access for hemodialysis. In a goat model of arteriovenous grafting, we have demonstrated sufficient mechanical characteristics of in situ engineered vascular grafts to allow safe vascular grafting with similar patency rates compared to ePTFE AV-grafts. This indicates that in situ TEBVs are a robust vascular graft, with the potential to be used in as arteriovenous vascular access for hemodialysis.

\section{Introduction}

The high failure rate of vascular access sites contributes to the rising cost of renal replacement therapy [1,2], a growing issue when combined with the increasing prevalence of end-stage renal disease [3]. Autologous vessels offer the best patency rates with regard to vascular grafting. However, preexisting disease, previous harvesting, and unsuitability for a vascular procedures limits their use [4]. Synthetic options however, are prone to infection, intimal hyperplasia (IH), and/or thrombosis [5,6]. Thus, tailor-made tissue-engineered blood vessels (TEBVs) may serve as a viable alternative to synthetic grafts.

A wide range of tissue-engineering approaches have been suggested for replacing synthetic grafts [7]. One such method involves the socalled mandril-based approach, which relies on the foreign body response (FBR) driving the development of an autologous in vivo cellularized vascular substitute surrounding an implanted medical device [8]. Using both in vivo [9,10] and in vitro [11] approaches, we previously reported that the implant's surface characteristics can influence the resulting FBR, thereby affecting the composition of the tissue that forms around the implant. Based on these studies, we found that subcutaneously implanted polymeric rods can elicit an FBR, resulting in the encapsulation of the rods with a fibrocellular tissue capsule that can then be grafted into the vasculature as a carotid interposition, enabling

\footnotetext{
* Corresponding author. Leiden University Medical Center, C7Q-36, Albinusdreef 2, 2333 ZA, Leiden, the Netherlands.

E-mail address: j.i.rotmans@lumc.nl (J.I. Rotmans).
} 
remodeling of the tissue into a vascular phenotype [9]. Moreover, our group has recently demonstrated that the presence of uremia does not impact the formation of the tissue capsules in vivo [12].

Here, we report the generation of functional TEBVs using a goat model of vascular grafting, and we describe the dynamic properties by which grafted TEBVs remodel to produce a suitable vascular phenotype. The arteriovenous grafting model was chosen as it allows the functional assessment of TEBVs in terms of vascular remodeling and patency in a rigorous setting.

\section{Methods}

\subsection{Study design}

All experiments were approved by the Animal Care and Use Committee of the University Medical Center Utrecht and were performed in accordance with Dutch and European legislation. The study included 17 adult female Dutch milk goats that were randomly divided into a TEBV group $(n=8)$ and an ePTFE control group $(n=9)$. Each animal received nadroparin (15,000 IU SID) starting the day after vascular grafting and clopidogrel (150 mg SID) after a loading dose of $300 \mathrm{mg}$ beginning 7 days prior to grafting and continuing until the animal was sacrificed. One day prior to surgery, the goats received a buprenorphine patch ( $5 \mu \mathrm{g} / \mathrm{h}$ delivery rate) and were fasted overnight. For the TEBV group, two cylindrical-shaped polymer rods were implanted subcutaneously in the neck. The neck was chosen as an implantation site as this allowed good surgical access to the carotid artery and jugular vein, from which an arteriovenous conduit could be grafted. In addition, implantation in the neck provided the option to check patency of the arteriovenous graft manually. One month later, the rods with tissue capsules grown around them were harvested, and one tissue capsule was grafted as an arteriovenous conduit between the carotid artery and jugular vein in the same goat. The cylindrical shaped tissue that forms around the implant is considered a tissue capsule, while it is considered a TEBV as soon as it is grafted into the vasculature. The other tissue capsule was used for histology, mechanical testing, thrombogenicity assays, and cell culture experiments. In three animals, an additional rod was implanted during the grafting operation to ensure that one month after grafting a TEBV, TC, and artery could be harvested for use in the thrombogenicity assay (see Fig. 1).

Patency of the graft was monitored weekly using ultrasonography with a CX50 ultrasound machine (Philips, Eindhoven, the Netherlands). One and two months after grafting, 5 and 3 animals, respectively, were euthanized and the grafts were removed for histological analysis, thrombogenicity assays, and cell culture experiments. Pre-grafted tissue capsules were compared to post-grafted tissue capsules for their ability to remodel within the vasculature. In contrast, the control group received a 6-mm ePTFE graft placed between the carotid artery and jugular vein; this graft was left in place for one or two months $(n=6$ and $\mathrm{n}=3$, respectively), after which the animals were euthanized and the grafts were removed for histological analysis and thrombogenicity assays.

\subsection{Production of polymer rods}

Cylindrical solid rods ( $6 \mathrm{~mm}$ in diameter and $6 \mathrm{~cm}$ in length) were fabricated using a specially designed mold at the MERLN Institute for Technology-Inspired Regenerative Medicine, Maastricht, the Netherlands. The rods were composed of the co-polymer poly(ethylene oxide terephthalate)-poly (butylene terephthalate) (PEOT/PBT; PolyVation, Groningen, the Netherlands) with a weight ratio of PEOT/ PBT of 55/45 and an initial molecular weight of $300 \mathrm{~g} / \mathrm{mol}$. In brief, polymer pellets were heated to $165^{\circ} \mathrm{C}$, injected into the mold, and allowed to gradually cool before removing the rods. The rods were then cleaned with $70 \%$ ethanol, the tips were rounded in order to facilitate implantation, and the surface of the rods was modified as described previously $[9,10]$. The rods were briefly submerged in chloroform, washed, and then dried under nitrogen gas. The surface topography of the rods was confirmed using SEM analysis. The rods could not be broken with the application of manual pressure. Due to a single faulty polymer batch, rod breaking was an issue in a subset of implants, these rods were excluded from the analysis performed here.

\subsection{Surgical procedures}

Two polymeric rods were implanted in the neck of each goat by making a small incision and bluntly preparing a subcutaneous pocket approximately $9 \mathrm{~cm}$ in length. For the animals used in the thrombogenicity assay $(n=3)$, an additional rod was implanted during the vascular grafting surgery. Each rod was secured to the surrounding subcutaneous tissue using 2-0 Prolene sutures at both ends. One month after implantation, the neck was opened via a midline incision and the polymer rods-including the surrounding tissue capsules-were removed by gentle dissection, after which the rod was extruded easily from the tissue. The integrity of the tissue capsule was confirmed by inflation with saline, and the tissue capsule was then implanted as an end-to-side arteriovenous conduit between the carotid artery and the jugular vein using running 6-0 Prolene sutures. Flow was measured at the time of grafting and at termination using a perivascular probe. In a subset of animals, an angiogram was performed using a Allura Xper FD20 angiograph (Phillips) in order to confirm post-surgical positioning of the TEBV.

\subsection{Mechanical testing of tissue capsules}

All mechanical tests were performed in accordance with ISO-71981998 guidelines [13]. To measure suture retention strength, a suture was placed at three locations at a depth of $2 \mathrm{~mm}$ in the tissue using 5-0 Vicryl (Ethicon, Johnson \& Johnson) and pulled at a steady rate of $5.0 \mathrm{~mm} / \mathrm{min}$; the maximum force applied was recorded using a Kern $5 \mathrm{~K} 5 \mathrm{~N}$ hanging scale (Kern, Balingen, Germany) with a resolution of $0.05 \mathrm{~N}$. Prior to grafting, dynamic compliance was measured for a tissue capsule $6 \mathrm{~cm}$ in length, which was strained with a load of $0.5 \mathrm{~N}$ and placed in a specially designed compliance measurement system at $37 \pm 1{ }^{\circ} \mathrm{C}$; the sample was then subjected to a pulsatile pressure of $120 / 80 \mathrm{mmHg}$ at $1 \mathrm{~Hz}$. Pulsations were recorded using a high-definition microscope camera with an accuracy of $\pm 0.02 \mathrm{~mm}$, while simultaneously using a TruWave pressure transducer (Edwards Lifesciences, Irvine, CA) and a model 700G pressure gauge (Fluke, Eindhoven, the Netherlands). The temperature was recorded using a model PCE-779 N infrared thermometer (PCE instruments, Enschede, The Netherlands). Compliance of each vessel was determined by combining the high-definition images with the corresponding pressure data. To determine the vessel's bursting pressure, a $5-\mathrm{cm}$ tissue capsule was perfused with saline at $37 \pm 1{ }^{\circ} \mathrm{C}$ with steadily increasing pressure until the graft ruptured (Suppl. Video S1). Methylene blue was added to the saline solution in order to accurately determine the burst location and to confirm that the rupture did not occur at the vessel connectors. All ruptures occurred away from the connectors.

Supplementary data related to this article can be found at https:// doi.org/10.1016/j.biomaterials.2019.119577.

\subsection{Sample preparation and histology}

For histology and immunohistochemistry, tissues were fixed in $4 \%$ formaldehyde, processed, and embedded in paraffin. Cross-sections ( $5 \mu \mathrm{m}$ thickness) were cut from the tissue capsule before grafting, 1 month after grafting, and 2 months after grafting; these sections were used for thrombogenicity assays. Picrosirius red-stained sections were analyzed for the presence of collagen. A hematoxylin phloxine saffron (HPS) stain was used to assess cellular alignment. To examine cellular composition, immunohistochemistry was performed using the 


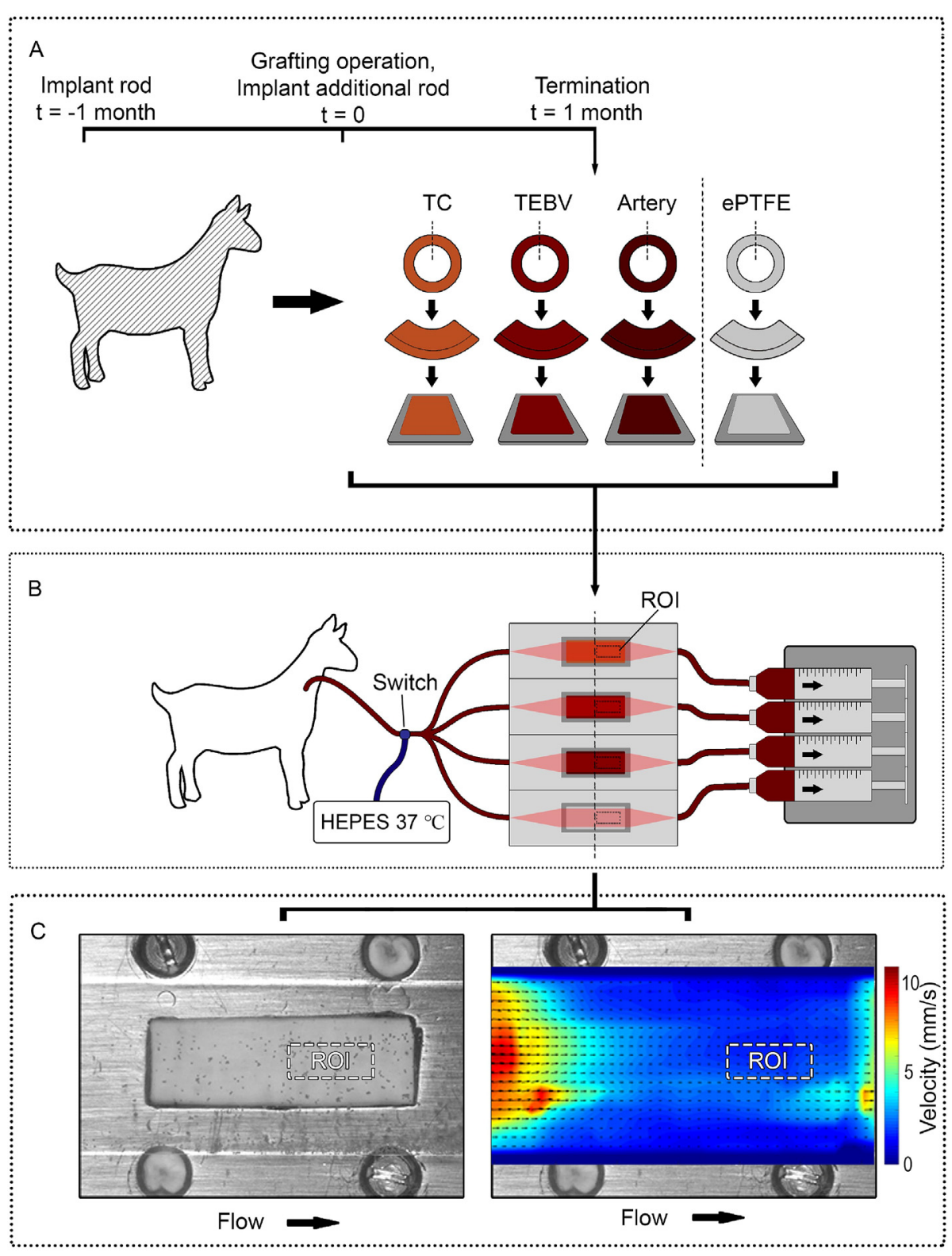

Fig. 1. Schematic overview of the experimental setup used for the thrombogenicity assay performed on explanted samples. A) In 3 animals, an additional rod was implanted during the grafting surgery $(\mathrm{t}=0)$; at $\mathrm{t}=1$ month a TEBV, TC, and artery were harvested from a single animal. A sterile new piece of ePTFE was used as a control. The vessel samples were cut open and placed longitudinally in a sample holder chip with the sample's lumen exposed. The samples were immersed in HEPES buffer at all times during handling. B) The sample holders were placed in parallel in a specially designed ex vivo perfusion chambers. Blood from a second animal was perfused in parallel over the ROI in the chamber at a rate of $12.5 \mathrm{ml} / \mathrm{min}$, with blood being drawn from the animal into and into the syringes. After a total volume of $6.25 \mathrm{ml}$ had perfused over the chamber, $37^{\circ} \mathrm{C}$ HEPES was automatically perfused over the samples at $12.5 \mathrm{ml} / \mathrm{min}$ to wash the samples. C) Left: Image of tracer particles flowing through the chamber for particle image velocimetry. Right: Pseudocolor image showing the velocity fields generated by the samples; note that the flow is homogeneous at the ROI. following antibodies: $\alpha$-smooth muscle actin ( $\alpha$-SMA, Dako, Amstelveen, the Netherlands; 1:1000) for myofibroblasts; vimentin (Immunologic, Duiven, the Netherlands; 1:100) for fibroblasts; desmin (Immunologic; 1:100), myosin (smooth muscle) heavy chain (Alfa Aesar, Karlsruhe, Germany; 1:200) for contractile vascular smooth muscle cells (VSMCs); Calprotectin (Bio-Rad, Munich, Germany; 1:100) for macrophages; and eNOS (BD, Vianen, the Netherlands; 1:2500), and Elastin (Sigma-Aldrich, Houten, the Netherlands; 1:2500) for endothelial cells. Each antibody was visualized using 3,3'-diaminobenzadine (DAB), and the sections were counterstained with hematoxylin. Where necessary, antigen retrieval was performed using heatinduced $0.1 \%$ trypsin. Fluorescence and bright-field images of the stained sections were obtained using a panoramic slide scanner (3DHistec, Budapest, Hungary). All stained sections were compared to their respective isotype controls and control tissues. To quantify the staining, the percentage of DAB positivity relative to the total area (for fibroblasts, myofibroblasts, and smooth muscle cells) was quantified using ImageJ software with three histological sections per sample. For each sample, a minimum of three histological sections (HPS staining) near the venous anastomosis were used to assess stenosis, in which the lumen surface area was compared (as a percentage) to the area of the original lumen.

\subsection{Contractility assay}

Primary VSMCs from a carotid artery, VSMC-like cells from a TEBV, and fibroblasts/myofibroblasts from a tissue capsule were isolated from two animals. If present, the endothelial monolayer was detached by gently scraping with sterile surgical forceps. Care was taken to ensure that the tissue from the tunica media of the artery and the luminal tissues of the TEBV and tissue capsule were isolated. The samples were dissected into small pieces and plated on $60-\mathrm{cm}$ Petri dishes pre-coated with collagen (Purecol, $10 \mu \mathrm{g} / \mathrm{ml}$ ). After 14 days in culture with DMEM/F12 medium supplemented with $10 \%$ fetal calf serum (FCS), $100 \mathrm{U} / \mathrm{ml}$ penicillin, and $100 \mu \mathrm{g} / \mathrm{ml}$ streptomycin, the cells were trypsinized and re-plated on 10-cm Petri dishes and cultured for an additional 7 days. At approximately $80 \%$ confluence, the cells were trypsinized and used for the contractility assay. The HFF1 cell line was used as a control and was cultured in DMEM supplemented with 10\% FCS, $100 \mathrm{U} / \mathrm{ml}$ penicillin, and $100 \mu \mathrm{g} / \mathrm{ml}$ streptomycin. For each sample, 20,000 cells were plated in triplicate on silicone elastomer dishes containing DMEM/F12 medium supplemented with $1 \%$ FCS, $100 \mathrm{U} / \mathrm{ml}$ 


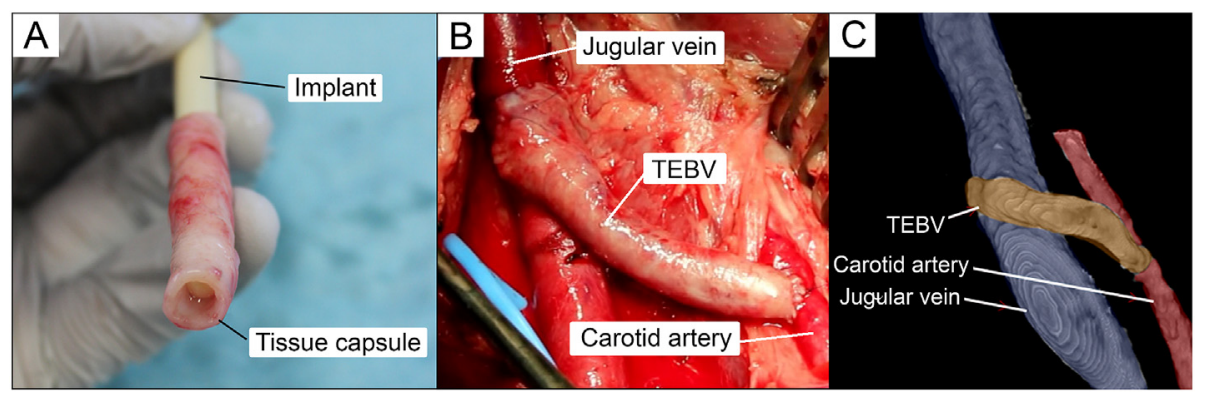

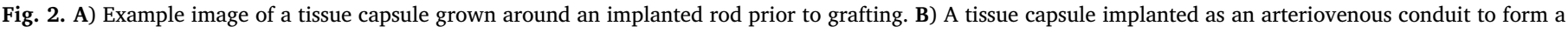
TEBV. C) Example angiogram used to assess the position of the TEBV.

penicillin and $100 \mu \mathrm{g} / \mathrm{ml}$ streptomycin. Deformable silicone elastomer (5 kPa) $24 \times 24 \mathrm{~mm}$ Petri dishes were coated overnight with collagen in serum-free DMEM/F12 prior to use. Twenty-four hours after the cells were plated, bright-field microscopy images were taken of ten random fields of view at $100 \times$ magnification. Sample contractility was determined by counting the number of contractile cells per field of view and is expressed relative to the total number of cells, as described previously [14]. Cell contractility was determined by the presence of visible deformations in the elastomer beneath the cells.

\subsection{Thrombogenicity assay}

One month after grafting, the animal was sacrificed and a 2-cm midgraft section of the TEBV, the un-operated contralateral carotid artery, and an ungrafted tissue capsule were removed $(n=3)$. Using great care, the samples were directly placed in $37^{\circ} \mathrm{C}$ HEPES buffer, and the tissue rings were cut open and placed into sample holders. Care was taken to ensure that the samples were not directly exposed to air. The sample holders were placed in a specially designed ex vivo perfusion chamber (Fig. 1A). A sterile new piece of ePTFE was used as a control. Blood was drawn from the jugular vein of a control animal that had received no therapeutics and was perfused at a rate of $12.5 \mathrm{ml} / \mathrm{min}$ over all samples in parallel using a syringe pump with a total volume of $6.25 \mathrm{ml}$ (Fig. 1B). The flow system was designed to ensure that all samples received exactly the same volume of blood and flow rate. Moreover, this flow rate allowed a stable shear rate of $20 \mathrm{dyn} / \mathrm{cm}^{2}$ to be attained in all chambers. After $30 \mathrm{~s}$ of perfusion, the samples were washed with $37^{\circ} \mathrm{C}$ HEPES buffer. The flow chamber was then opened, and each sample was divided into two sections. One section was washed in $37^{\circ} \mathrm{C}$ HEPES and fixed in $1 \%$ paraformaldehyde for confocal microscopy. The other section was washed in $37^{\circ} \mathrm{C}$ HEPES and fixed in glutaraldehyde for 2 days for SEM analysis. To examine luminal adhesiveness, SEM imaging was performed using an ROI in which the flow rate and shear stress were stable between samples based on our characterization experiments (Fig. 1C); thus, the same imaging location was used for all samples.

To investigate the flow characteristics of the ex vivo flow chamber, particle imagevelocimetry (PIV) was performed in separate experiments [15]. These measurements were performed using an ex vivo flow chamber that contained an ePTFE graft in the sample holder. A waterglycerol solution (with a density of $1100 \mathrm{~kg} / \mathrm{m}^{3}$ to mimic the viscosity of whole blood) was perfused at $37^{\circ}$ though the system to generate pressure-driven flow with a constant flow rate of $12.5 \mathrm{ml} / \mathrm{min}$ using a neMESYS pump (Cetoni, Korbussen, Germany). The solution was seeded with monodispersed polyethylene microspheres $(106-125 \mu \mathrm{m}$ diameter; Cospheric, Santa Barbara, CA). Images were recorded using a LaVision Imager sCMOS camera (sCMOS, 16-bit, $2560 \times 2160$ pixels, pixel pitch $6.5 \mu \mathrm{m}$ ). Image acquisition and PIV processing were performed using LaVision DaVis version 8.3 to create a flow field derived from the setup (Fig. 1C).

\subsection{Statistical analysis}

All summary data are presented as the mean \pm the standard error of the mean. Data for the mechanical tests were analyzed using the Mann-Whitney $U$ test using GraphPad Prism version 7.00. Differences with a $P$-value $<0.05$ were considered statistically significant.

\section{Results}

\subsection{Formation of the TEBVs}

The surface properties of the implanted rods were analyzed using scanning electron microscopy (SEM). Gamma irradiation did not affect the surface topography of the rods (data not shown). One month after implantation, a thick tissue capsule had formed around each implanted rod (Fig. 2A). This tissue capsule was easily removed from the rod, was easy to handle for surgical procedures, and was suitable for use in forming an arteriovenous conduit (Fig. 2B).

\subsection{Mechanical properties of the TEBVs}

The burst pressure, suture retention strength, and dynamic compliance of the TEBVs are summarized in Fig. S1. The burst pressure was $2382 \pm 129 \mathrm{mmHg}$; although this is lower than the burst pressure of a native human artery, it is higher than the burst pressure of a native human vein and far exceeds physiological blood pressure levels [16]. The suture retention strength of our TEBVs was $1.97 \pm 0.49 \mathrm{~N}$, with little variance between samples; this strength exceeds the requirements for safe grafting, which are generally defined by the mechanical properties of the saphenous vein $[7,16]$.

\subsection{Tissue capsule formation and remodeling to form a vascular phenotype}

Prior to grafting, the tissue capsule is composed of extracellular matrix components (Fig. 3), fibroblasts, and myofibroblasts (Fig. 4A-C), with several macrophages lining the inner layer (Fig. 3C). Collagen is also abundant in the TC, as shown using picrosirius red staining (Fig. 3D). In contrast, the tissue capsule does not contain elastin (Fig. 3A) or an endothelial lining (Fig. 3B) prior to grafting. The eNOSpositive cells in the pre-grafted tissue capsule are attributed primarily to capillaries, confirming that the tissue capsule is well-vascularized (Fig. 3). Extremely few foreign body giant cells were observed; however, the presence of calprotectin-positive cells (Fig. 3C) indicates the presence of macrophages in the luminal region. The majority of cells present in the tissue capsule are vimentin-positive, $\alpha$-SMA-positive, desmin-positive fibroblasts and myofibroblasts (Fig. 4A-C); however, at this stage the cells lack the features of contractile smooth muscle cells (e.g., they do not express myosin heavy chain (HC)) (Fig. 4D).

After grafting, the tissue capsule underwent remodeling, forming a thick-walled graft. One month after grafting, the majority of cells in the inner lining of the TEBV were vimentin-positive, $\alpha$-SMA-positive, and 


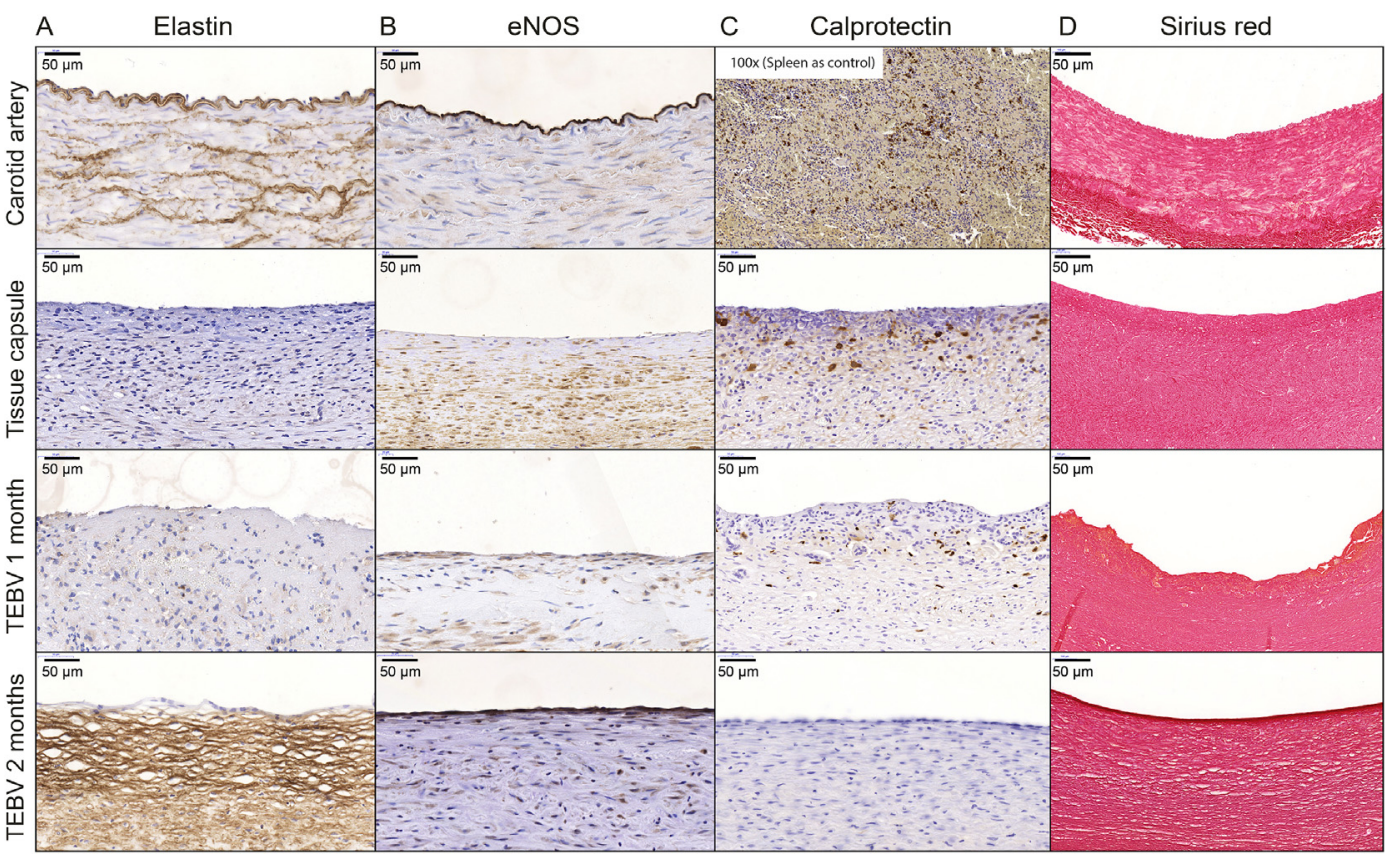

Fig. 3. Mid-graft cross-sections showing a notable increase in elastin expression (A), a clearly defined endothelial monolayer (B), an absence of inflammatory cells two months after grafting (C), and an abundance of collagen (D).

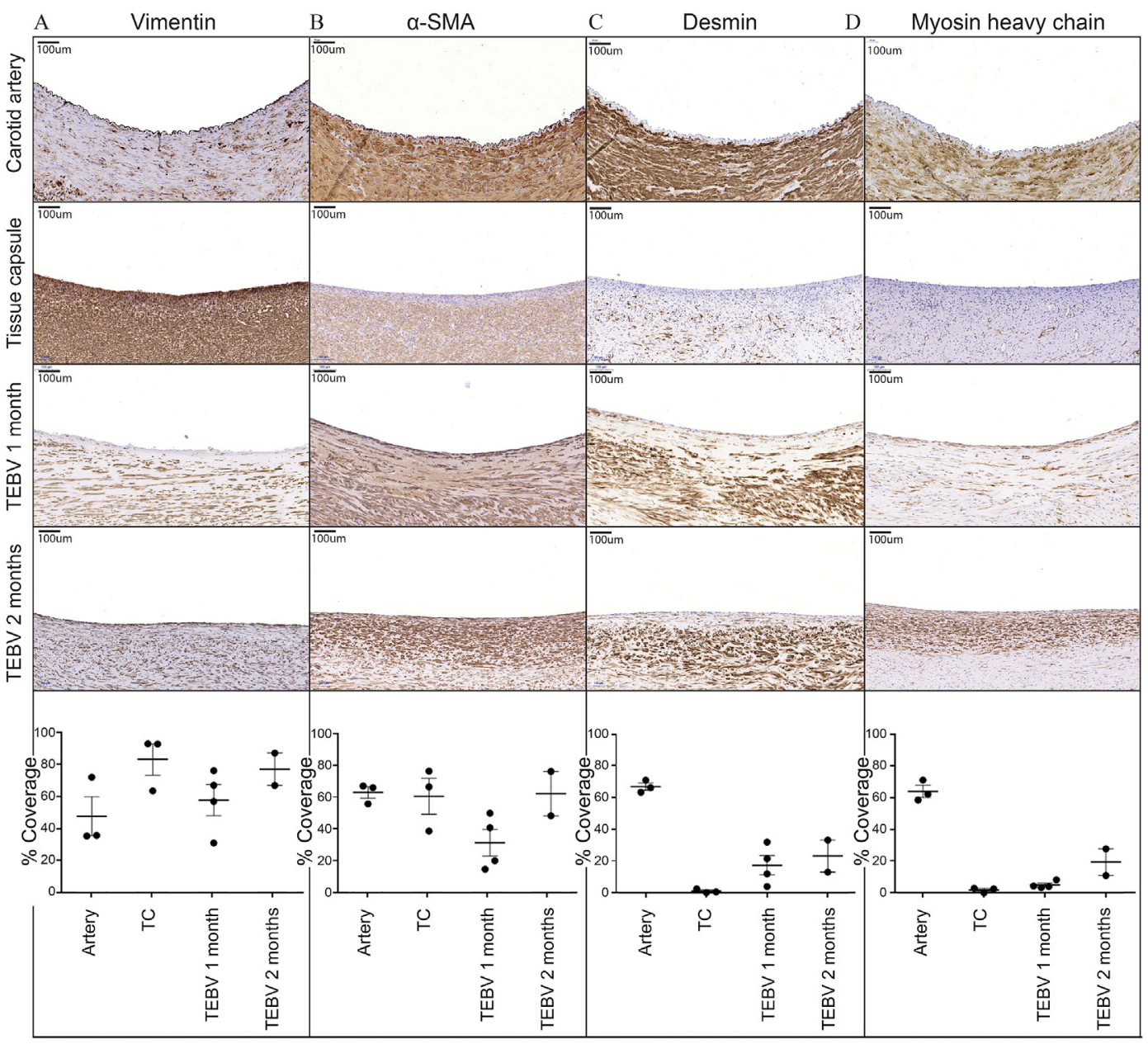

Fig. 4. Immunohistochemistry showing the cellular composition of native arteries, tissue capsules, TEBVs at 1 month, and TEBVs at 2 months. 


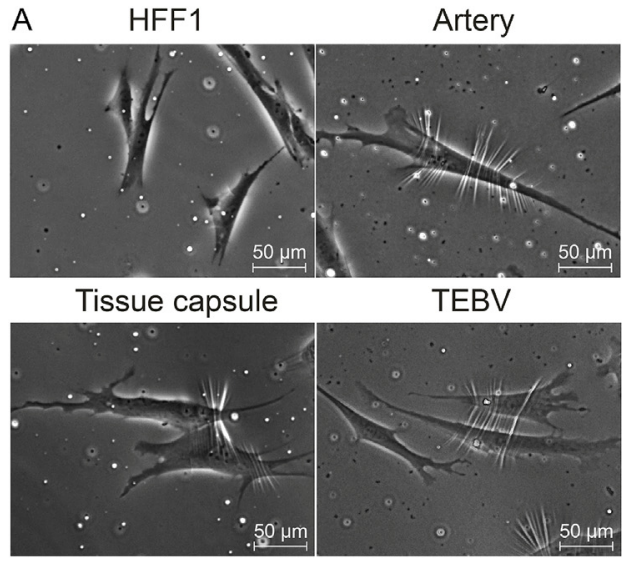

B

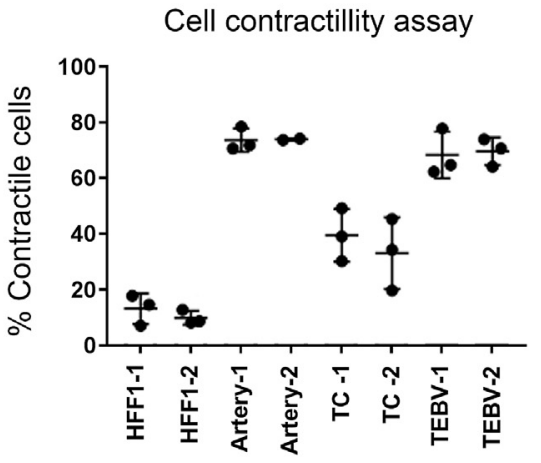

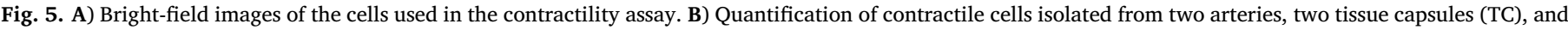

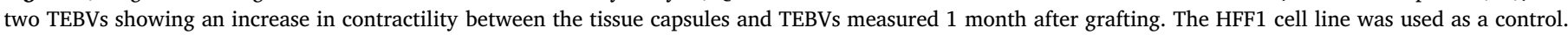

desmin-positive (Fig. 4A-D), consistent with smooth muscle cell-like properties; interestingly, however, some of the cells were also myosinHC-positive. Two months after grafting, nearly all of the cells in the inner lining of the graft were strongly myosin-HC-positive (Fig. 4D). Moreover, at 1 month, the tissue capsules lacked elastin; in contrast, the tissue capsule expressed high levels of elastin 2 months after grafting (Fig. 3). Of note, the distribution of elastin varied throughout the vessel (Fig. S2), consistent with the putative contribution of elastin formation to the TEBV's hemodynamic properties. In addition, the VSMC (vascular smooth muscle cell)-like cells are circumferentially aligned (Fig. S3B), closely mimicking the morphology of mature arterial cells (Fig. S3C).

One month after grafting, isolated and cultured luminal cells have a notable increase in contractility compared to cells isolated prior to grafting (Fig. 5A-B). This finding supports the histologically identified contractile phenotype.

\subsection{Thrombogenicity assay and characterization of the ex vivo whole blood perfusion chamber}

Next, we performed an ex vivo thrombogenicity assay in order to determine whether the endothelium present in the TEBVs (see Fig. 3) confers anti-thrombotic properties to the vessel's surface. The perfusion chambers used in the assay were capable of perfusing four samples in parallel, with a constant flow rate and equal blood volume (Fig. 1B), while using a small $(10 \mathrm{~mm} \times 5 \mathrm{~mm})$ patch of tissue. The tissue samples exposed to whole blood flow were then compared to separate samples that were not perfused.

We then examined the flow characteristics of the ex vivo flow chamber using particle image velocimetry (PIV) and found that the flow was stable in the region of interest (ROI) with minimal fluctuations in flow velocity. The mean velocity in the ROI was $2 \mathrm{~mm} / \mathrm{s}$, and the corresponding Reynolds number was 0.733; thus, the flow is laminar, steady, and reproducible. We used a standardized flow rate of $12.5 \mathrm{ml}$ / min in the system, generating an average wall shear stress in the ROI of $1.44 \mathrm{~N} / \mathrm{m}^{2}\left(14.4 \mathrm{dyn} / \mathrm{cm}^{2}\right)$; this is comparable to the time-averaged arterial shear stress levels (Fig. 1C). SEM analysis revealed that ex vivo perfusion of our samples caused a notable decrease in the adhesive capacity of the tissue capsule's luminal surface after it had been grafted and exposed to the circulation for one month, as compared to the nongrafted tissue capsules which had not been exposed to the circulation. Exposing pre-grafted tissue capsules to non-anticoagulated whole blood drawn directly from the jugular vein of a goat caused the complete coverage of the tissue with thrombocytes and fibrin; no adhesion of fibrin and thrombocytes occurred when exposing carotid artery samples to exposed to blood (Fig. 6A). In contrast, no blood components adhered to TEBVs obtained 1 month after vascular grafting (Fig. 6A-B), confirming that the eNOS-positive endothelial lining on the TEBV's luminal surface is functional (Fig. S5). Importantly, two ePTFE samples did not have adherence, although a protein/fibrin-rich structure adhered to a third ePTFE sample (Fig. 6A and $\mathrm{C}_{3}$ ). Our analysis revealed that primarily erythrocytes were present in the artery sample (Fig. $6 \mathrm{C}_{1}$ ).

\subsection{Patency of TEBV grafts and ePTFE grafts}

Lastly, we compared patency between our TEBV grafts and synthetic ePTFE grafts; the results are summarized in Table 1. One month after vascular grafting, 4 of the 5 TEBV grafts and 5 of the 6 ePTFE grafts remained patent; two months after grafting, 2 out of 3 TEBV grafts and 1 out of 3 ePTFE grafts were still patent. At 1 month, stenosis in the non-occluded (i.e., patent) TEBV grafts was higher than in the nonoccluded ePTFE grafts $(52.22 \pm 29.10 \%$ versus $4.17 \pm 1.95 \%$, respectively); in contrast, at 2 months stenosis in the TEBV grafts was lower than in the ePTFE grafts $(12.94 \pm 16.19 \%$ versus $85.61 \%$, respectively) (Table 1). The stenoses in both the TEBV and ePTFE grafts formed primarily near the venous anastomosis, and in the venous outflow tract. The majority of cells in the stenotic lesions near the venous anastomosis were vimentin- and $\alpha$-SMA-positive fibroblasts and calprotectin-positive macrophages (Fig. 7 and Fig. S6). Moreover, none of the TEBV or ePTFE grafts developed calcification (Fig. S7).

\section{Discussion}

Here, we report that engineered TEBVs can be generated by in vivo remodeling of autologous fibrocellular tissue capsules. Notably, our TEBVs have low thrombogenicity and is composed of cells with a functional contractile phenotype. Moreover, the pre-grafted tissue capsules exhibit sufficient mechanical properties to restrain arterial pressure. At this stage, the tissue capsules are composed primarily of fibrocellular tissue with very little elastin; therefore, the dynamic compliance of the tissue capsules is lower than that of a native artery. Importantly, the patency rate was similar between TEBV grafts and synthetic ePTFE grafts both one and two months after vascular grafting. Growing the tissue capsule within the subcutaneous space over a 1month period facilitated the growth of an autologous, cellularized TEBV that has sufficient mechanical strength and can be successfully grafted into the vasculature. In a previous study we have already demonstrated the capacity of the TEBV to be successful cannulated, with a time to hemostasis of only $3 \mathrm{~min}$ [9]. Moreover, these TEBV can remodel to form a vascular phenotype with VSMC-like properties and a functional endothelial layer, which were confirmed using histology and a novel thrombogenicity assay.

Prior to vascular grafting, the tissue capsules were composed primarily of fibroblasts, myofibroblasts, and collagen. Fibroblasts are characterized by remarkable plasticity [17-19], with the ability to 

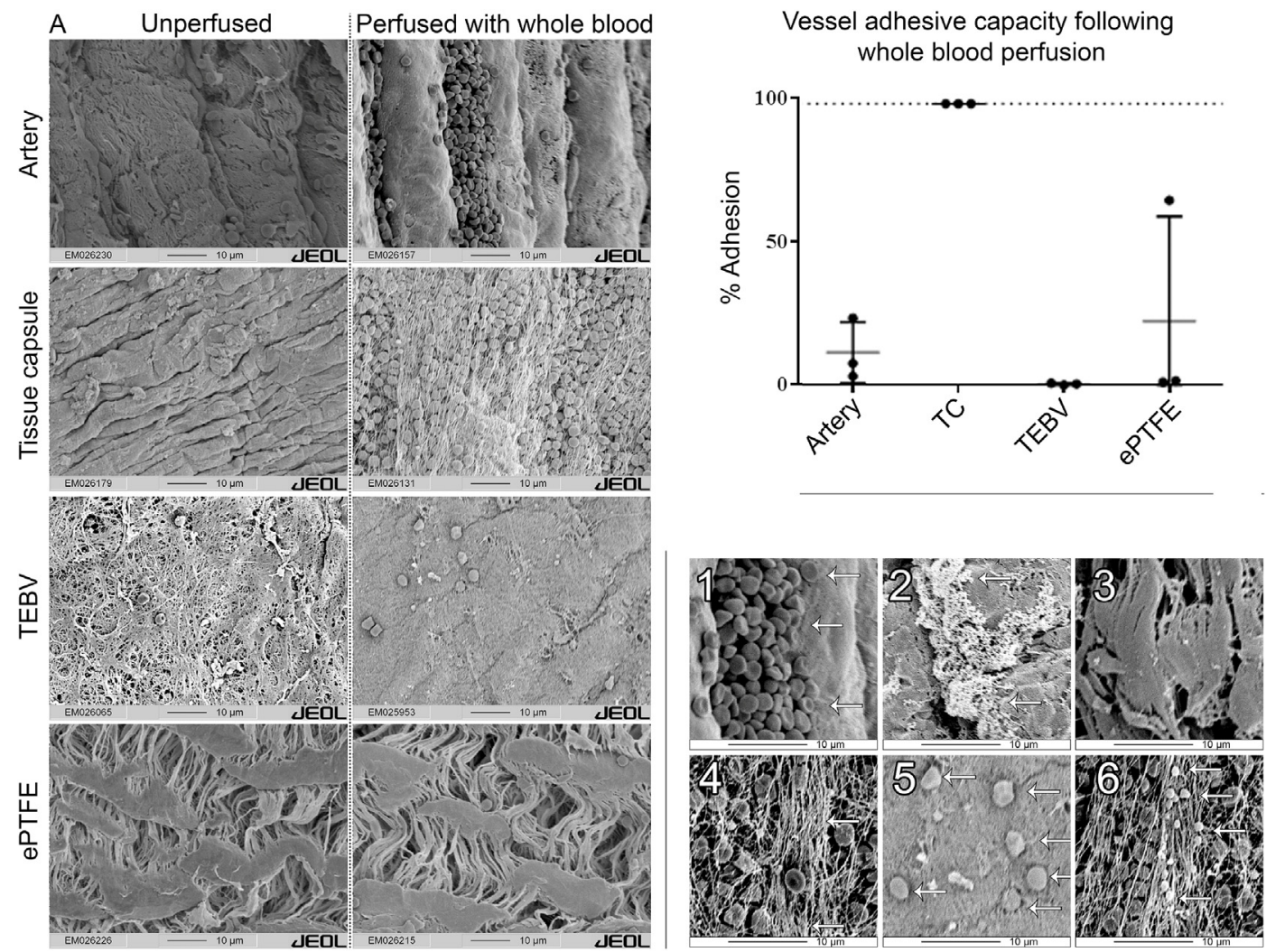

Fig. 6. A) Example SEM images of the indicated tissues before (left column) and after (right column) laminar whole blood perfusion at arterial shear. After perfusion, the arterial sample contains only erythrocytes gathered in the folds of the artery. The perfused tissue capsule sample is completely covered in shear-aligned fibrin fibers with numerous erythrocytes and some thrombocytes. The TEBV sample has only minor adhesion of compounds. Finally, the ePTFE sample has extremely little adhesion of compounds. B) Quantification of adhesion before and after flow. Note the drastic decrease in the adhesive capacity of the TEBV one month after grafting. C) Detailed images of adherent structures (arrows) observed after the various tissues were perfused. $\mathbf{C}_{1}$ : The arterial tissue has erythrocytes adhered to it. $\mathbf{C}_{2}$ : Example ePTFE covered with fibrin fibers that were possibly degraded by fibrinolytic enzymes. $\mathbf{C}_{3}$ : Example of an ePTFE sample containing non-descript adherent structures. $\mathrm{C}_{4}$ : A tissue capsule sample showing shear-aligned fibrin structures that have captured red blood cells. $\mathbf{C}_{5}$ : Example TEBV showing adherent non-erythrocyte cells, which were possibly monocytes or endothelial progenitor cells. $\mathrm{C}_{6}$ : A tissue capsule sample with attached thrombocytes.

Table 1

Summary of the patency and stenosis rates of TEBVs and ePTFE grafts harvested one or two months after grafting.

\begin{tabular}{|c|c|c|c|}
\hline & $\begin{array}{l}\text { Number of } \\
\text { grafts }\end{array}$ & Patent & $\begin{array}{l}\% \text { Stenosis }^{\mathrm{a}} \text { (mean } \pm \text { Standard error } \\
\text { of the mean) }\end{array}$ \\
\hline TEBV 1 month & 5 & 4 & $52.2 \pm 14.6$ \\
\hline TEBV 2 months & 3 & 2 & $12.9 \pm 11.5$ \\
\hline ePTFE 1 month & 6 & 4 & $4.2 \pm 1.2$ \\
\hline ePTFE 2 months & 3 & 1 & 85.6 \\
\hline
\end{tabular}

${ }^{a}$ Only the patent grafts were included in this analysis. SEM, standard error of the mean. differentiate into VSMCs [20]. Even though the initial tissue capsule was composed almost entirely of fibroblasts and numerous luminal macrophages, within a month of vascular grafting the tissue capsules began to show a notable increase in desmin-positive VSMC-like cells, as well as a notable decrease in macrophages. Two months after grafting, the number of myosin-HC-positive cells had increased further, and a clearly defined endothelial lining with confirmed anti-thrombogenic properties was present. Importantly, virtually no macrophages were observed at this stage. Based on functionality, protein expression, and the cell types present, the densely cellularized nature of the tissue capsule clearly resulted in the capsule's differentiation into a vascular phenotype upon exposure to hemodynamic factors. Whether the VSMClike cells originated from infiltrating cells or differentiated from

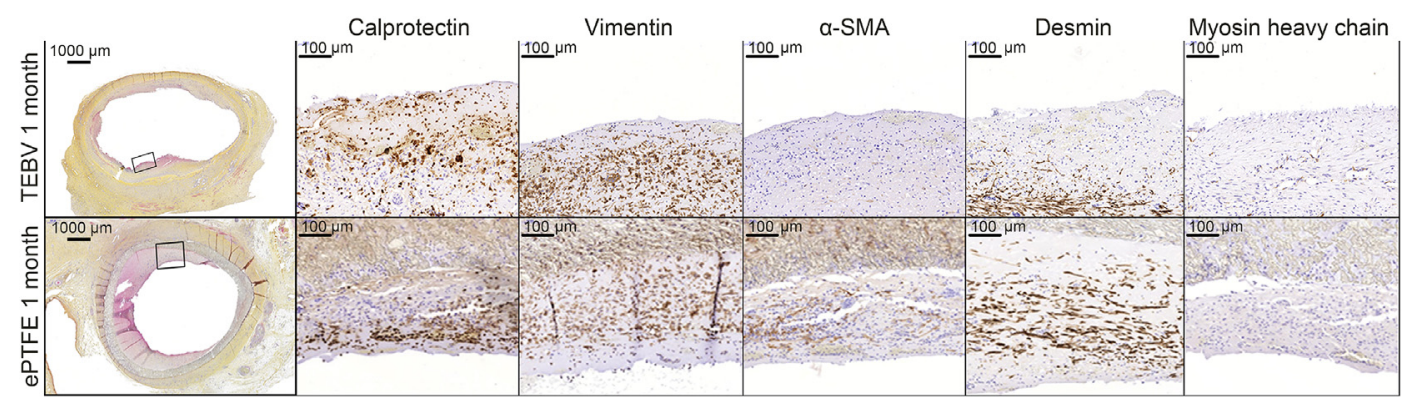

Fig. 7. Example cross-sections of stenotic lesions in a TEBV and ePTFE obtained one month after grafting, with immunohistochemistry to stain various cell types present in the lesion. Overall, the cellular composition was similar between the two lesions. 
fibroblasts/myofibroblasts present in the tissue capsule is currently unclear. Similarly, the origin of the endothelial cells is unclear, as they may have been derived from endothelial progenitor cells (EPCs) [21] or via ingrowth from the artery and/or vein [22]. Pre-seeding the luminal surface of a vascular graft with endothelial cells is both labor-intensive and costly and requires access to a well-equipped facility [23]. In this respect, an autologous, cellularized graft can be reendothelialized more easily, thereby providing long-term patency. Moreover, our finding that the cells are distributed uniformly two months after grafting indicates a morphological shift from the initial cells in the tissue capsule to VSMClike cells. Finally, we found no signs of calcification in either the TEBV or ePTFE grafts.

In native blood vessels, the vascular endothelium plays an essential role in preventing the formation of intimal hyperplasia (IH), thrombosis, and calcification [23]. At the time of vascular grafting, the tissue capsules lacked an endothelial lining of the luminal surface. However, because the surface of the tissue capsule is rich in collagen, tissue factors, and ECM components, it is intrinsically thrombogenic material. Using a pig model of arterial interposition grafting, we previously reported that the tissue capsule becomes endothelialized following vascular grafting [9]. Using a parallel ex vivo flow experiment under controlled standardized circumstances, we now report that the TEBV has reduced adhesive properties after vascular grafting compared to the initial, pre-grafted tissue capsule. This change may be attributed to the formation of an endothelial layer monolayer that closely mimics a native artery within two months of grafting.

Compelling evidence suggests that both fibrin and platelets are essential for the endothelialization that occurs in our model. After exposure to whole blood, a structure formed that was based on the direction of flow and consisted of aligned fibrin, erythrocytes, and platelets. Importantly, this process did not result in acute thrombus formation in the grafted TEBVs, despite starting low molecular-weight heparin (LMWH) therapy only the day after surgery. The animals had however received clopidogrel prior to surgery. This indicates the possibility that the thrombogenic response of the tissue capsule's surface may be stabilized in an acute setting. Using a model of vascular injury, fibrin and platelets were found to play an essential role in recruiting endothelial progenitor cells (EPCs) and promoting their differentiation into mature endothelial cells $[24,25]$. Thus, the initial thrombogenic layer observed in the tissue capsules may be essential for either promoting the future endothelialization of the lumen and/or recruiting circulating cells to the TEBV [13].

Despite having similar patency, venous stenosis remained an issue in both TEBV and ePTFE grafts. In both groups, the stenotic lesions occurred either near the venous anastomosis or directly at the venous outflow tract. Moreover, the lesions in both groups contained randomly aligned fibroblasts, myofibroblasts, VSMC-like cells, and macrophages, all of which are characteristic of IH [26]. A decrease in the stenotic lesion in the TEBV at the 2-month time point compared to the 1-month time point was observed. This decrease in stenotic lesion area is not completely understood however it may be due to the progressive remodeling of the tissue over time. In the context of an arteriovenous fistula, wall shear stress increases considerably; when combined with turbulent flow, this can cause damage to endothelial cells and initiate the formation of IH [27-29]. Wall shear stress is an important factor in the development of IH [30-32]; therefore, the presence of a functional endothelium may reduce the risk of $\mathrm{IH}$.

In addition to compliance mismatch [33] and turbulent flow $[28,34-36]$, the inflammatory foreign body response caused by ePTFE is considered a contributing factor to graft failure $[37,38]$. On the other hand, removal of possible foreign body inflammatory factors-as in our TEBV method-does not entirely eliminate $\mathrm{IH}$, underscoring the greater importance that compliance and hemodynamic factors play in graft occlusion compared to inflammation, at least in the setting of vascular access for hemodialysis. Thus, innovative new strategies to modulate flow and/or turbulence at the vascular access site, as well as anti- proliferative strategies, may help improve the long-term durability of the graft.

A possible limitation of using goats as a model is their tendency for relatively rapid stenosis formation and graft occlusion. Furthermore, the high degree of inter-individual variation among goats and sheep with respect to thrombogenicity [39] underscores the importance of directly comparing patency with an ePTFE-based vascular graft or other relevant control. The variable degree of thrombogenicity of the vasculature, as well as the lack of response to acetylsalicylic acid, was a reason that LMWH was administered to the animals, providing additional evidence of the dissimilarity between patients and conventional animal models with respect to the vasculature. In contrast, both dogs and baboons are less prone to developing $\mathrm{IH}$ [40]. Therefore, the characteristics of the animal model, the study outcomes, and the corresponding control group must be taken into consideration when attempting to translate the results to the broader research field. Moreover, although no chronic kidney failure was induced in this study, we have recently reported that the presence of uremia does not impact the formation of the tissue capsules [12].

In the late 1960s, Sparks published the first attempt to use an autologous FBR-based tissue graft grown around a Dacron mesh substrate [41]. However, incomplete understanding of the FBR, together with the incorporation of foreign body materials into the engineered tissue, led to the occurrence of graft rupture and aneurysm formation [42]. Later, Campbell further developed this concept by using the peritoneal cavity as the in vivo bioreactor [43]. As the knowledge regarding modulation of the FBR increased, this so-called mandril-based method has been fine-tuned and strengthened [8].

The advantage of the approach used in our study compared to other tissue-engineering techniques is that autologous cellularized tissue is generated entirely in vivo, without the need for expensive and timeconsuming in vitro steps, the need for host cell invasion of decellularized scaffolds, or patient variability with respect to replacement of a degradable scaffold. We show that our autologous TEBVs can undergo remodeling within the vasculature, resulting in endothelialization and the production of VSMC-like cells. Moreover, our method does not require a maturation period, as the TEBVs can be implanted with predetermined dimensions tailor-made to the needs of the individual patient. Despite its promise, the patient's age [44], gender [45], and health status [46] can affect the FBR, and these factors must be taken into consideration when investigating the clinical relevance of this technique.

Based on these results, a clinical trial is currently being initiated to examine the functionality of in vivo engineered TEBVs as arteriovenous grafts in hemodialysis patients. Initially, tissue capsule formation in dialysis patients will be evaluated to determine if safe grafting can be performed. If the tissue is indeed deemed safe for vascular grafting, the tissue capsules will be grafted as arteriovenous conduit for hemodialysis vascular access.

In conclusion, our results provide compelling evidence that our in vivo engineered TEBVs can be implemented as arteriovenous vascular access. Using a robust ex vivo perfusion model, we confirmed that the newly formed endothelium is non-thrombogenic. Moreover, we show that our TEBVs undergo cellular reorganization to produce a vascular morphology with elastin formation, and we show that the cells differentiate into a VSMC-like phenotype. Despite the presence of stenosis in the TEBV grafts, the patency rate was similar to ePTFE grafts, indicating that our in vivo engineered TEBVs may serve as a viable arteriovenous conduit, or arterial bypass grafts.

\section{Funding}

This research was funded by a VIDI grant (016.156.328 to JIR) from ZonMw (The Netherlands Organization for Health Research and Development). 


\section{Author contributions}

W.J.G. - conception; data acquisition, analysis, interpretation; manuscript writing. K.E.A.B, T.C.R, F.F.R.D, J.F.H, C.D.M, M.S.A, H.C.B, B.H, A.K, C.P, A.J.Z, A.J.R.- data acquisition, interpretation. T.R - data acquisition. L.M - conception; data acquisition, analysis, interpretation. J.I.R - conception; data acquisition, analysis, interpretation; manuscript writing.

\section{Competing financial interests}

The authors declare no competing financial interests.

\section{Data availability}

All relevant data supporting the findings of this study are either included within the article and its Supplementary Information files or available upon request from the corresponding author.

\section{Acknowledgments}

We are grateful to R.A. Lalai for assistance with the analytical procedures used in this study. We thank E.F.J Overmars for technical assistance with respect to flow characterization. Finally, we thank the Department of Instrumental Affairs at Leiden University Medical Center for the technical assistance with respect to the materials used in this study, and we thank the biotechnology staff of the GDL Utrecht University for assistance with the animal studies.

\section{Appendix A. Supplementary data}

Supplementary data to this article can be found online at https:// doi.org/10.1016/j.biomaterials.2019.119577.

\section{References}

[1] J.J. Leermakers, et al., Cost-effectiveness of vascular access for haemodialysis: arteriovenous fistulas versus arteriovenous grafts, Eur. J. Vasc. Endovasc. Surg. 45 (1) (2013) 84-92.

[2] H.I. Feldman, et al., Hemodialysis vascular access morbidity in the United States, Kidney Int. 43 (5) (1993) 1091-1096.

[3] N.R. Hill, et al., Global prevalence of chronic kidney disease - a systematic review and meta-analysis, PLoS One 11 (7) (2016) e0158765.

[4] T.C. Rothuizen, et al., Arteriovenous access failure: more than just intimal hyperplasia? Nephrol. Dial. Transplant. 28 (5) (2013) 1085-1092.

[5] R.D. Sayers, et al., Long-term results of femorotibial bypass with vein or polytetrafluoroethylene, Br. J. Surg. 85 (7) (1998) 934-938.

[6] B.S. Dixon, et al., Effect of dipyridamole plus aspirin on hemodialysis graft patency, N. Engl. J. Med. 360 (21) (2009) 2191-2201.

[7] S. Pashneh-Tala, S. MacNeil, F. Claeyssens, The tissue-engineered vascular graftpast, present, and future, Tissue Eng. B Rev. 22 (1) (2016) 68-100.

[8] W.J. Geelhoed, L. Moroni, J.I. Rotmans, Utilizing the foreign body response to grow tissue engineered blood vessels in vivo, J. Cardiovasc. Transl. Res. 10 (2) (2017) 167-179.

[9] T.C. Rothuizen, et al., Development and evaluation of in vivo tissue engineered blood vessels in a porcine model, Biomaterials 75 (2016) 82-90.

[10] T.C. Rothuizen, et al., Tailoring the foreign body response for in situ vascular tissue engineering, Tissue Eng. C Methods 21 (5) (2015) 436-446.

[11] F.F. Damanik, et al., Towards an in vitro model mimicking the foreign body response: tailoring the surface properties of biomaterials to modulat extracellular matrix, Sci. Rep. 4 (2014) 6325.

[12] T. Bezhaeva, et al., Contribution of bone marrow-derived cells to in situ engineered tissue capsules in a rat model of chronic kidney disease, Biomaterials 194 (2018) $47-56$.

[13] H.C. de Boer, et al., Activated platelets correlate with mobilization of naive $\mathrm{CD} 34(+)$ cells and generation of $\mathrm{CD} 34(+) / \mathrm{KDR}(+)$ cells in the circulation. A meta-regression analysis, J. Thromb. Haemost. 11 (8) (2013) 1583-1592.

[14] J.M. Goffin, et al., Focal adhesion size controls tension-dependent recruitment of $\alpha$ smooth muscle actin to stress fibers, J. Cell Biol. 172 (2) (2006) 259-268.

[15] R.J. Adrian, J. Westerweel, Particle Image Velocimetry, Cambridge Univ. Press, 2010.

[16] G. Konig, et al., Mechanical properties of completely autologous human tissue engineered blood vessels compared to human saphenous vein and mammary artery, Biomaterials 30 (8) (2009) 1542-1550.

[17] J.K. Lighthouse, E.M. Small, Transcriptional control of cardiac fibroblast plasticity, J. Mol. Cell. Cardiol. 91 (2016) 52-60.

[18] S. Van Linthout, K. Miteva, C. Tschope, Crosstalk between fibroblasts and inflammatory cells, Cardiovasc. Res. 102 (2) (2014) 258-269.

[19] J.J. Tomasek, et al., Myofibroblasts and mechano-regulation of connective tissue remodelling, Nat. Rev. Mol. Cell Biol. 3 (5) (2002) 349-363.

[20] X. Liu, et al., Induced differentiation of human gingival fibroblasts into VSMC-like cells, Differentiation 95 (2017) 1-9.

[21] M. Avci-Adali, G. Ziemer, H.P. Wendel, Induction of EPC homing on biofunctionalized vascular grafts for rapid in vivo self-endothelialization - a review of current strategies, Biotechnol. Adv. 28 (1) (2010) 119-129.

[22] Y. Kouchi, et al., Apparent blood stream origin of endothelial and smooth muscle cells in the neointima of long, impervious carotid-femoral grafts in the dog, Ann. Vasc. Surg. 12 (1) (1998) 46-54.

[23] E.T. Goh, et al., Accelerating in situ endothelialisation of cardiovascular bypass grafts, Int. J. Mol. Sci. 16 (1) (2014) 597-627.

[24] H. Langer, et al., Adherent platelets recruit and induce differentiation of murine embryonic endothelial progenitor cells to mature endothelial cells in vitro, Circ Res. 98 (2) (2006) e2-10.

[25] H.F. Langer, et al., Platelet-induced differentiation of endothelial progenitor cells, Semin. Thromb. Hemost. 33 (2) (2007) 136-143.

[26] L. Li, et al., Neointimal hyperplasia associated with synthetic hemodialysis grafts, Kidney Int. 74 (10) (2008) 1247-1261.

[27] M.K. Fitts, et al., Hemodynamic shear stress and endothelial dysfunction in hemodialysis access, Open Urol. Nephrol. J. 7 (Suppl 1 M5) (2014) 33-44.

[28] H. Haruguchi, S. Teraoka, Intimal hyperplasia and hemodynamic factors in arterial bypass and arteriovenous grafts: a review, J. Artif. Organs 6 (4) (2003) 227-235.

[29] S.L. Meyerson, et al., The effects of extremely low shear stress on cellular proliferation and neointimal thickening in the failing bypass graft, J. Vasc. Surg. 34 (1) (2001) 90-97.

[30] K.S. Cunningham, A.I. Gotlieb, The role of shear stress in the pathogenesis of atherosclerosis, Lab. Investig. 85 (1) (2005) 9-23.

[31] H.M. Honda, et al., A complex flow pattern of low shear stress and flow reversa promotes monocyte binding to endothelial cells, Atherosclerosis 158 (2) (2001) 385-390.

[32] C. Hahn, M.A. Schwartz, Mechanotransduction in vascular physiology and atherogenesis, Nat. Rev. Mol. Cell Biol. 10 (1) (2009) 53-62.

[33] P.D. Ballyk, et al., Compliance mismatch may promote graft-artery intimal hyperplasia by altering suture-line stresses, J. Biomech. 31 (3) (1998) 229-237.

[34] S. Sivanesan, et al., Flow patterns in the radiocephalic arteriovenous fistula: an in vitro study, J. Biomech. 32 (9) (1999) 915-925.

[35] A. Remuzzi, M. Bozzetto, Biological and physical factors involved in the maturation of arteriovenous fistula for hemodialysis, Cardiovasc Eng Technol 8 (3) (2017) 273-279.

[36] B. Ene-Iordache, A. Remuzzi, Blood flow in idealized vascular access for hemodialysis: a review of computational studies, Cardiovasc Eng Technol 8 (3) (2017) 295-312.

[37] P. Roy-Chaudhury, et al., Venous neointimal hyperplasia in polytetrafluoroethylene dialysis grafts, Kidney Int. 59 (6) (2001) 2325-2334.

[38] P. Roy-Chaudhury, et al., Back to the future: how biology and technology could change the role of PTFE grafts in vascular access management, Semin. Dial. 25 (5) (2012) 495-504.

[39] A. Weigand, et al., New aspects on efficient anticoagulation and antiplatelet strategies in sheep, BMC Vet. Res. 9 (2013) 192.

[40] J.I. Rotmans, Animal models for studying pathophysiology of hemodialysis access, Open Urol. Nephrol. J. 7 (14-21) (2014).

[41] C.H. Sparks, Autogenous grafts made to order, Ann. Thorac. Surg. 8 (2) (1969) 104-113.

[42] R. Guidoin, et al., [The Sparks-Mandril arterial prosthesis. An ingenious concept, a total failure. What can we learn from it?], J. Mal. Vasc. 9 (4) (1984) 277-283.

[43] W.L. Chue, et al., Dog peritoneal and pleural cavities as bioreactors to grow autologous vascular grafts, J. Vasc. Surg. 39 (4) (2004) 859-867.

[44] D. Hachim, et al., Effects of aging upon the host response to implants, J. Biomed. Mater. Res. A 105 (5) (2017) 1281-1292.

[45] H. Dao Jr., R.A. Kazin, Gender differences in skin: a review of the literature, Gend. Med. 4 (4) (2007) 308-328.

[46] N. Maroz, R. Simman, Wound healing in patients with impaired kidney function, J. Am. coll. Clin. Wound Spec. 5 (1) (2013) 2-7. 